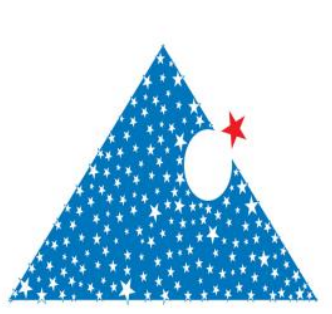

Www.dergipark.gov.tr

ISSN:2148-3736

El-Cezerî Fen ve Mühendislik Dergisi

Cilt: 6, No: 2, 2019 (251-258)

El-Cezerî Journal of Science and Engineering

Vol: 6, No: 2, 2019 (251-258)

DOI : $10.31202 /$ ecjse.476577

ECJSE

Research Paper / Makale

\title{
Investigation of Elastic Anisotropy Pressure Change in Al-Sc Alloys
}

\author{
Hamza Yaşar OCAK ${ }^{1}$ * , Gencer SARIOĞLU ${ }^{2}$, Salih AKBUDAK ${ }^{3}$, Gökay UĞUR ${ }^{4}$ and Şule UĞUR ${ }^{4}$ \\ ${ }^{1}$ Faculty of Science and Art, Department of Physics, Dumlupınar University, Kütahya, 43000, Turkey \\ ${ }^{2}$ Gediz Vocational School, Occupational Health and Safety, Dumlupinar University, Kütahya, 43600, Turkey \\ ${ }^{3}$ Faculty of Science and Art, Department of Physics, Adiyaman University, Adiyaman, 02040, Turkey \\ ${ }^{4}$ Faculty of Science and Art, Department of Physics, Gazi University, Ankara, 06500, Turkey \\ *hyasar.ocak@dpu.edu.tr
}

Received/Geliș: 30.10 .2018

Accepted/Kabul: 09.04.2019

\begin{abstract}
To calculate the anisotropy of Al-Sc alloys under high pressure, the second order elastic constants were obtained from the density functional theorem (DFT) using the EMTO module. The elastic constants of the $\mathrm{Al}-1.1 \mathrm{Sc}$ and $\mathrm{Al}-1.9 \mathrm{Sc}$ alloys in cubic, fcc, structure were examined depending on the pressure. The elastic constants of both alloys vary greatly depending on the applied pressure. Elastic constants obtained due to pressure, center elastic anisotropy $(A)$ were used to calculate defined anisotropy $\left(\mathrm{A}_{\mathrm{CNNF}}\right)$ parameters for the closest neighboring interactions. Anisotropy parameters changed according to both Sc rate and pressure and the pressure was closer to each other for increasing values. What makes this work special is the detailed examination of anisotropy in Al-Sc alloys for the first time depending on the pressure.
\end{abstract}

Keywords: Al-Sc, Elastic Constant, Elastic Anisotropy, Pressure, Bulk Constants.

\section{Al-Sc Alaşımlarında Elastik Anizotropi Basınç Değişimininin İncelenmesi}

\begin{abstract}
Öz: Al-Sc alaşımlarının anizotropisini yüksek basınç altında hesaplamak için, ikinci dereceden elastik sabitleri EMTO modülü kullanılarak yoğunluk fonksiyonel teoreminden (DFT) elde edildi. Al-1.1Sc ve Al-1.9Sc alaşımlarının kübik, fcc, yapıdaki elastik sabitleri, basınca bağlı olarak incelenmiştir. Her iki alaşımın elastik sabitleri, uygulanan basınca bağlı olarak büyük ölçüde değişir. Basınç nedeniyle elde edilen elastik sabitler, en yakın komşu etkileşimler için tanımlı anizotropi $\left(\mathrm{A}_{\mathrm{CNNF}}\right)$ parametrelerini hesaplamak için merkez elastik anizotropi (A) kullanılmıştır. Anizotropi parametreleri hem Sc hızına hem de basınca göre değişti ve değerleri artırmak için basınç birbirine daha yakındı. Bu çalışmayı özel kılan, Al-Sc alaşımlarında anizotropilerin, basınca bağlı olarak ilk defa detaylı bir şekilde incelenmesidir.
\end{abstract}

Anahtar Kelimeler: Al-Sc, Elastik Sabit, Elastik Anizotropi, Basınç, Kütle Sabitleri.

\section{Introduction}

Al-based alloys are among the most important raw materials of the industry and experimental and theoretical studies on these alloys are continuing [1]. Al-Sc alloys are also used in different fields in the industry due to their lightness and elasticity [2]. The smoothness of crystal structures, small particle size, ductility and super plastic properties make these alloys more useful [3-6]. Many of the experimental studies on this subject include x-ray analysis (XRD) and are supported by theoretical results. Although the Sc element (hcp) in these alloys is dissolved in $\mathrm{Al}$ (fcc) element at very low rate $(23 \%)$, it increases the strength considerably. Scandium not only strengthens in strength but also increases the recrystallization at low rates, leading to a significant reduction in crystal sizes [7]. It is known that the solid phase of Al-Sc alloys is in L12 phase and it belongs to space group Pm-

Ocak H.Y., Sarıoglu G., Akbudak S., Uğur G., Uğur Ş., "Investigation of Elastic Anisotropy Pressure Change in Al-Sc Alloys”, El-Cezerî Journal of Science and Engineering, 2019, 6(2); 251-258. 
$3 \mathrm{~m}$ [7-9]. The formation of Al-Sc alloys and mechanical properties were also investigated by experimental methods [10-12]. The particle and grain sizes of these alloys, recrystallization conditions, different crystalline precipitates, stress and strain effects, boundary magnitudes, diffusion properties, macro and micro structures and kinetic properties of the boundaries were studied at different temperatures [13-16]. Theoretically, studies on Al-Sc alloys are ongoing [9-13]. Although these theoretical studies were mostly related to the mechanical properties of the alloys, there was no comprehensive study on elastic anisotropy. However, although Y. H. Duan and colleagues have investigated some elastic properties of $\mathrm{Al}_{3} \mathrm{Sc}$ structure under high pressure [17], such a study has not been found in the main phases of Al-Sc alloys. In theoretical studies, elastic anisotropies are calculated as a function of mechanical properties. However, some researchers have examined the elastic anisotropy in detail under high pressure for the closest neighboring interactions between the surface, height and central force [18-20].

In this study, the anisotropy parameters of the main phase of Al-Sc alloys will be calculated and the contribution of Sc atom in anisotropy will be investigated. The second order elastic constants [9] in the equilibrium state of Al-1.1 Sc and Al-1.9 Sc alloys are the main parameters of this study. This type of work is important because it will be the first for these alloys. For this purpose, the elastic anisotropy of the Al-1.1Sc and Al-1.9Sc alloys (A) and the anisotropies defined for the closest neighboring interaction under the central force $\left(\mathrm{A}_{\mathrm{CNNF}}\right)$ effect of the elastic anisotropies and surface changes $\left(\Delta_{\mathrm{S} 1}\right.$ and $\left.\Delta_{\mathrm{S} 2}\right)$ were calculated separately. The effect of Sc ratio was also examined in all calculations.

\section{Material and Methods}

In this study, the second degree elastic constants of Al-1.1Sc and Al-1.9Sc alloys at room temperature were obtained by EMTO method [9]. These results for Al-1.1Sc: $\mathrm{C}_{11}=104.35 \mathrm{GPa}$, $\mathrm{C} 12=65.7 \mathrm{GPa}, \mathrm{C}_{44}=47.05 \mathrm{GPa}$ and Al-1.9Sc: $\mathrm{C}_{11}=104.3 \mathrm{GPa}, \mathrm{C}_{12}=65.6 \mathrm{GPa}$ and $\mathrm{C}_{44}=46.72$ $\mathrm{GPa}$. In the same study, the fcc structure of both alloys was determined by XRD analysis [9]. It is very difficult for a crystal to remain un-polarized under the influence of internal and external forces. The crystalline cubic structure does not mean that it is isotropic. In order for a crystal to be isotropic it must be $\mathrm{C}_{12}=\mathrm{C}_{44}$. In these alloys, it is certain that both elastic constants are quite different and the samples are anisotropic. Because, cubic crystals are not independent from the direction of their elastic properties such as hardness, shear and volume constants. These anisotropy parameters can be calculated by many different methods, regardless of the directions. These are the parameters of Every (AE) and Zener (AZ) anisotropy, defined as $\mathrm{AE}=0$ and $\mathrm{AZ}=1$ [27]. Anisotropy parameters are calculated in three different directions in non-cubic crystals. Also for the cubic crystals, the Voigt-Reuss-Hill anisotropy parameter $\left(\mathrm{A}_{\mathrm{VRH}}\right)$ is obtained depending on the slip constants that $\mathrm{A}_{\mathrm{VRH}}=0$ is the ideal result [9].

In order to be able to calculate the anisotropy parameters at high pressure, firstly the second degree elastic constants should be calculated at high pressure. For this purpose, by using the second degree elastic constants [9] calculated in equilibrium conditions, Murnaghan [21] and Birich-Murnaghan equations for elastic constants were used and the second degree elastic constants under high pressure were calculated separately for both alloys;

$$
\begin{aligned}
& C_{i j}=C_{0}+C_{0}^{\prime} C_{0}\left(\frac{\Delta V}{V_{0}}\right)+\frac{1}{2} C_{0}^{\prime} C_{0}\left(C_{0}^{\prime}+1\right)\left(\frac{\Delta V}{V_{0}}\right)^{2}+\frac{1}{6} C_{0}^{\prime} C_{0}\left(C_{0}^{\prime}+1\right)\left(C_{0}^{\prime}+2\right)\left(\frac{\Delta V}{V_{0}}\right)^{3} \\
& P(V)=\frac{3}{2} C_{0}\left[\left(\frac{V_{0}}{V}\right)^{\frac{7}{3}}-\left(\frac{V_{0}}{V}\right)^{\frac{5}{3}}\right]\left\{1+\frac{3}{4}\left(4-C_{0}^{\prime}\right)\left[\left(\frac{V_{0}}{V}\right)^{\frac{5}{3}}-1\right]\right\}
\end{aligned}
$$


Here, $\mathrm{C}_{\mathrm{ij}}$ is $\mathrm{C}_{11}, \mathrm{C}_{12}$ and $\mathrm{C}_{44}$ respectively, $C_{0}^{\prime}$ is the derivatives of the second order elastic constants in equilibrium state, $\frac{\Delta V}{V_{0}}$ pressure induced strain and $\Delta \mathrm{V}=\mathrm{V}-\mathrm{V}_{0}$ is the change in volume. Firstly, the volumes of the crystals were obtained from the equation (2) depending on the theoretical pressures applied to the crystal in equilibrium and second degree elastic constants were calculated by the equation (1). The theoretical high pressure applied to the crystal was limited to $100 \mathrm{GPa}$, because the volume constants of these alloys were smaller than $90 \mathrm{GPa}$ [9]. The results of these calculations are given in Figures 1 and 2. The volume constants of the crystals were calculated separately both from $B=\left(C_{11}+2 C_{12}\right) / 3$ equation and from the equation (1). And results were tested given in Figure 3.

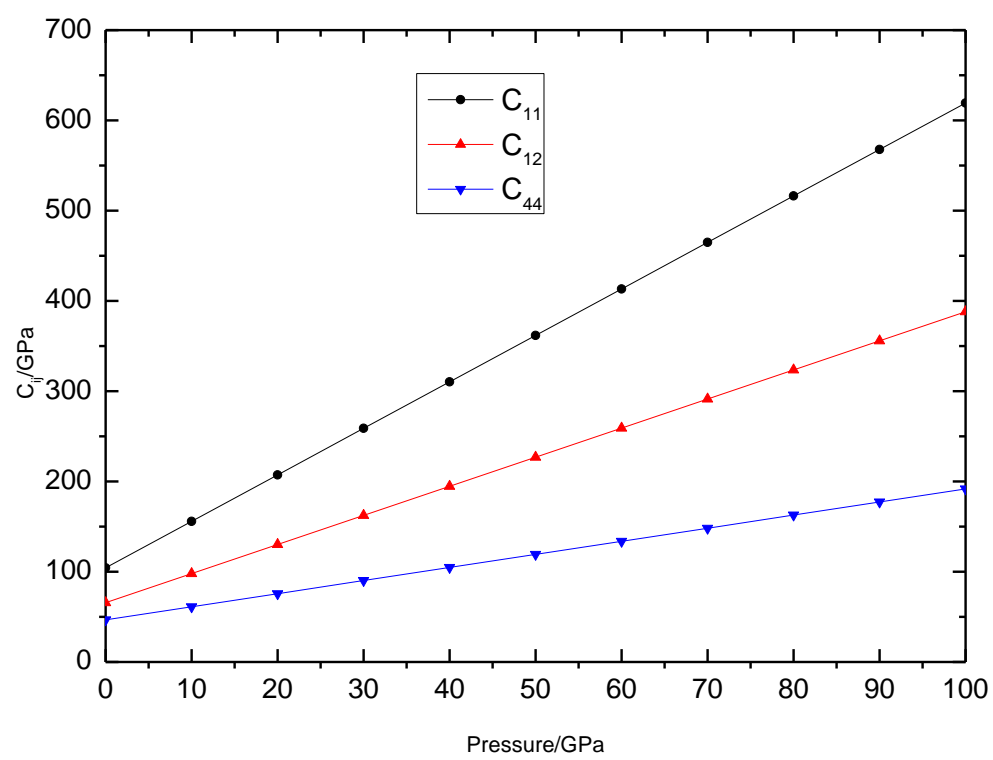

Figure 1. Change of elastic constants with respect to pressure for Al-1.1Sc alloy

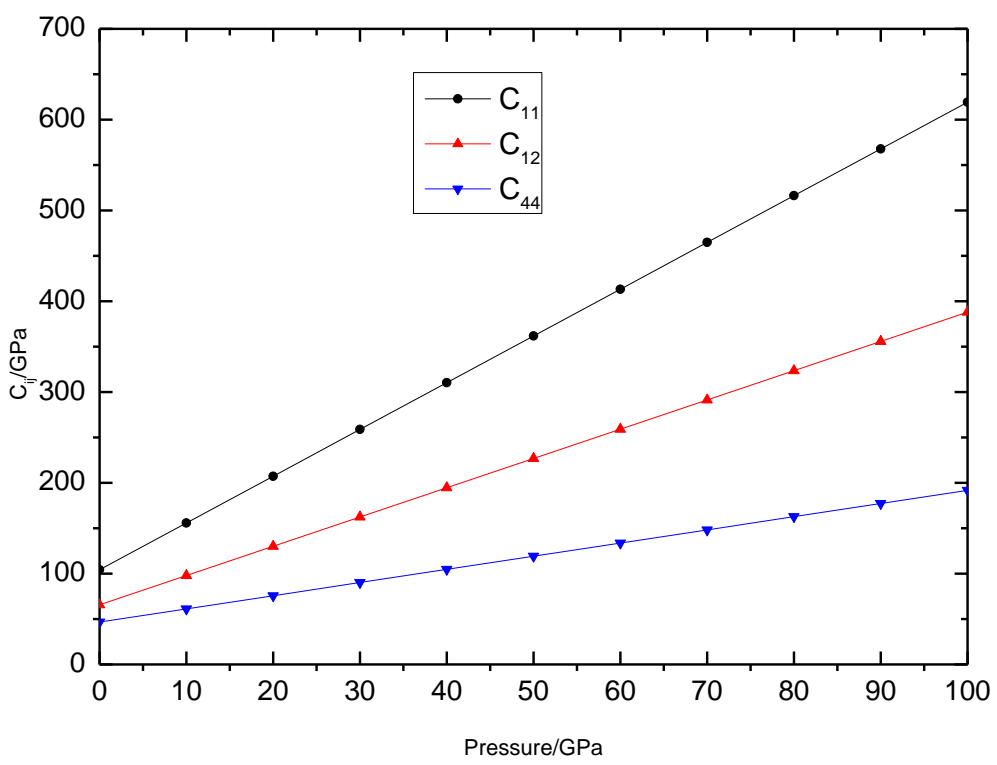

Figure 2. Change of elastic constants with respect to pressure for Al-1.9Sc alloy

Anisotropy parameter for a cubic crystal is also defined as follows; Depending on this definition, polarization in anisotropy is defined as the surface and length polarization in anisotropy [20]. 
Longitudinal polarization $\Delta_{\mathrm{P}}$, and surface polarizations are caused by shear stresses on the surface. It has two orientations (Shear Anisotropy) such as $\Delta_{\mathrm{S} 1}$ ve $\Delta_{\mathrm{S} 2}$.

$$
\begin{aligned}
A & =\frac{2 C_{44}+C_{12}}{C_{11}}-1 \\
\Delta_{p} & =\frac{2 A}{3}, \quad \Delta_{S 1}=-\frac{A}{2}, \quad \Delta_{S 2}=-\frac{3 A}{8}
\end{aligned}
$$

The results calculated according to these equations are given in Figures 3-5.

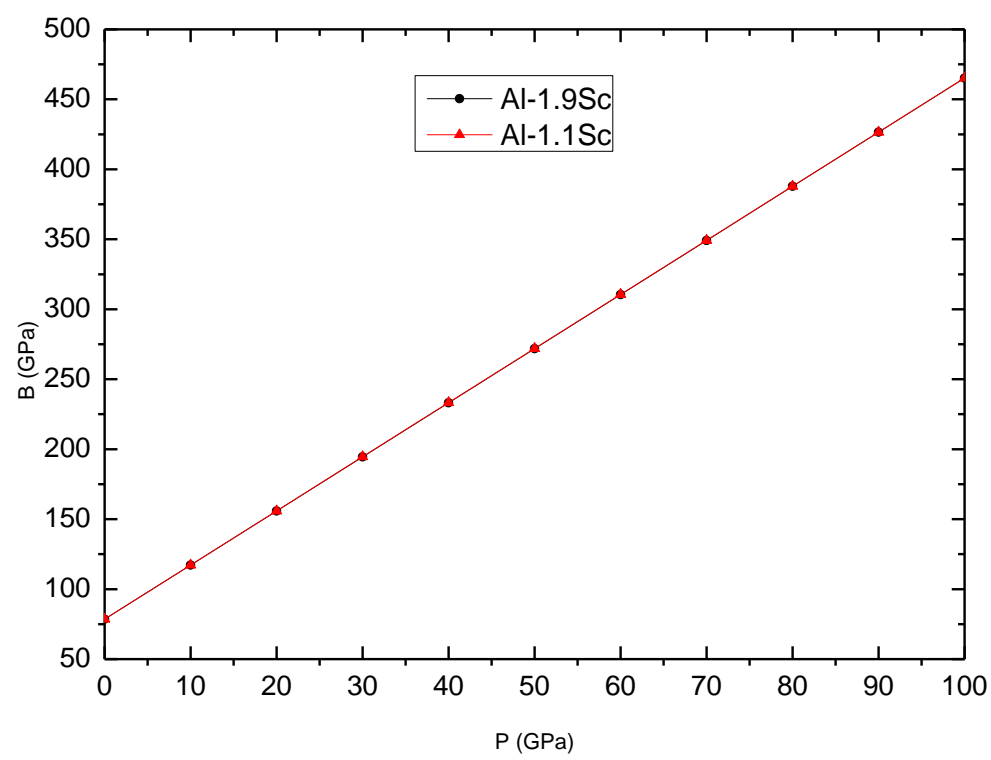

Figure 3. Change of volume constants with respect to pressure for Al-1.1Sc and Al-1.9Sc alloys.

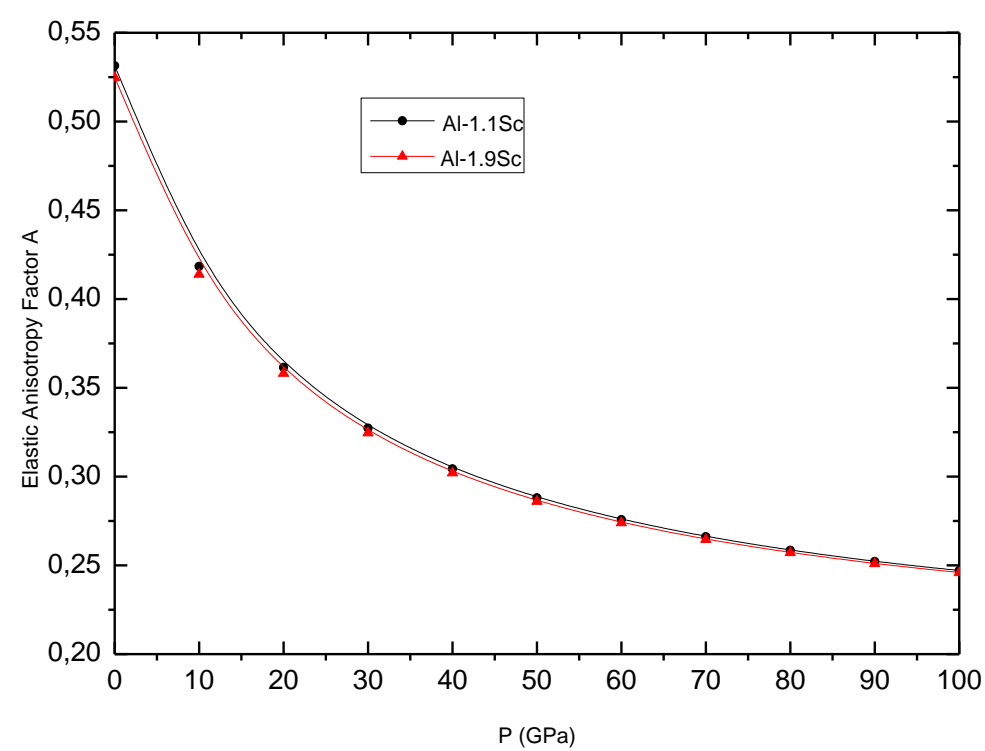

Figure 4. Change of anisotropy for Al-1.1Sc and Al-1.9Sc alloys. 


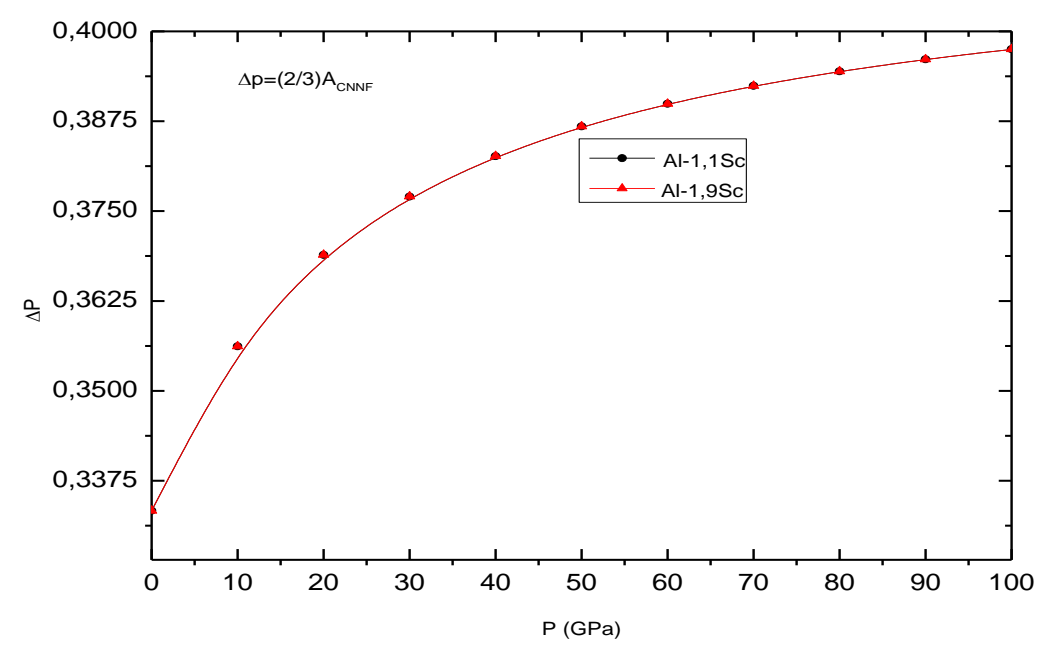

Figure 5. Change of longitudinal anisotropy for Al-1.1Sc and Al-1.9Sc alloys.

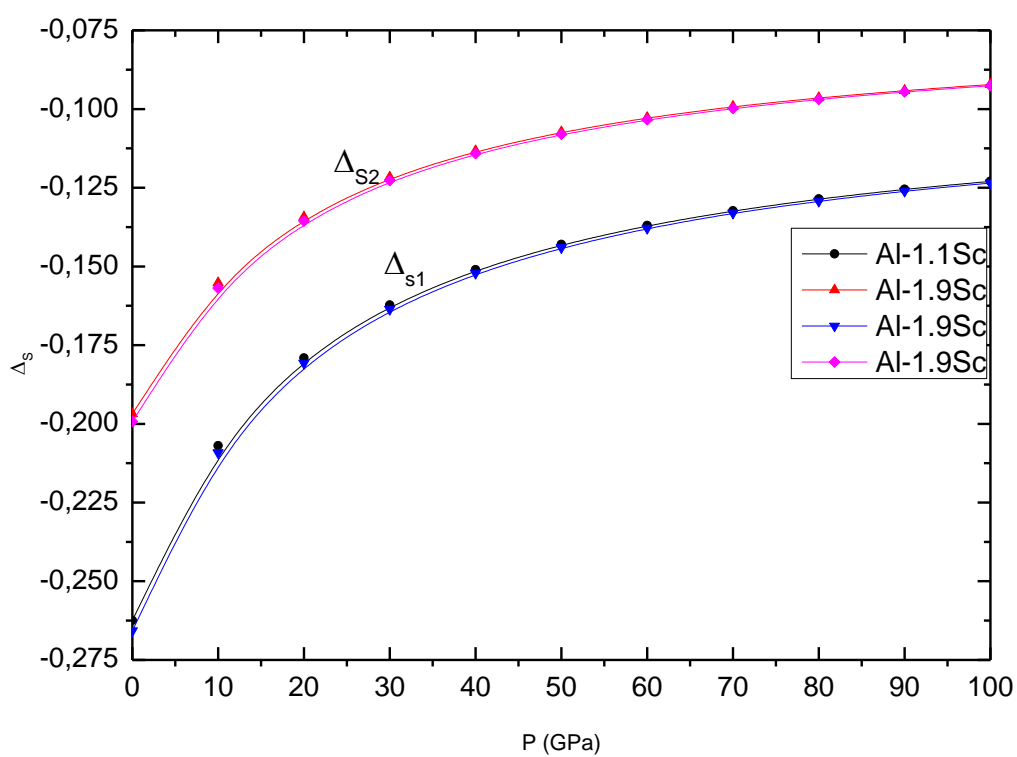

Figure 6. Shear Change for Al-1.1Sc and Al-1.9Sc alloys.

The anisotropy parameter resulting from the closest neighbor interactions in the central force effect is calculated for the cubic crystals [20] with the following equation and the results are given in Figure 6.

$$
A_{C N N F}=\frac{1-\frac{P}{C_{11}}}{2}
$$

In addition, the $A_{E}, A_{Z}$ and $A_{V R H}$ anisotropy parameters defined in the literature are calculated from the following equations [22] and results are given in Figure 7.

$$
\begin{aligned}
& A_{E}=\frac{C_{11}-C_{12}-2 C_{44}}{\left(C_{11}-C_{12}\right)} \\
& A_{Z}=\frac{2 C_{44}}{\left(C_{11}-C_{12}\right)}
\end{aligned}
$$




$$
A_{V R H}=\frac{G_{V}-G_{R}}{G_{V}+G_{R}}
$$

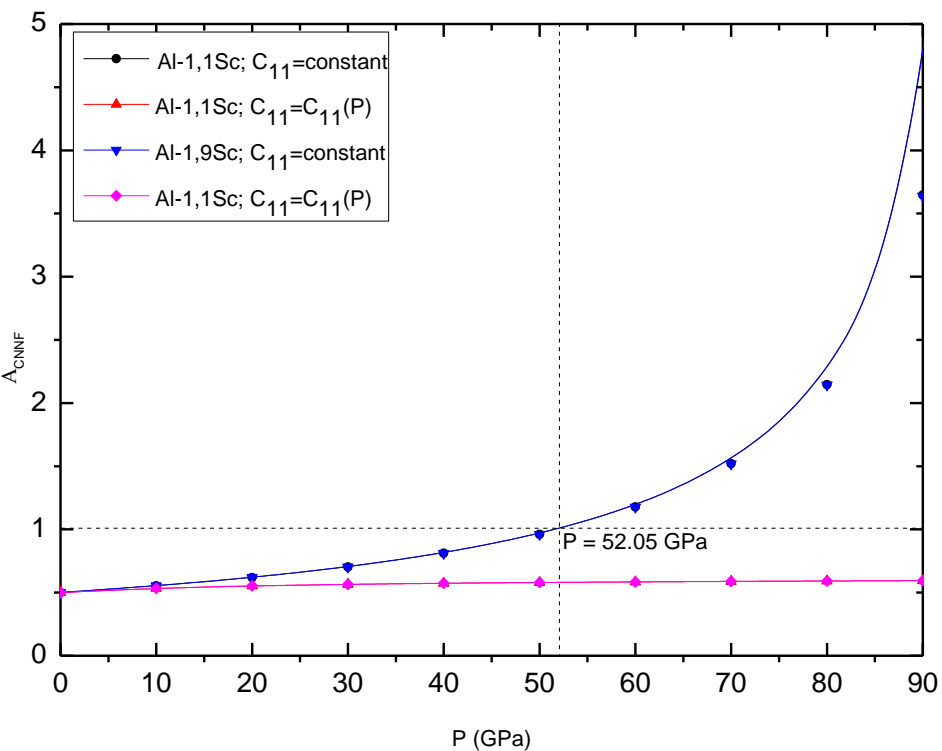

Figure 7. Central exchange anisotropy changes for Al-1.1Sc and Al-1.9Sc alloys.

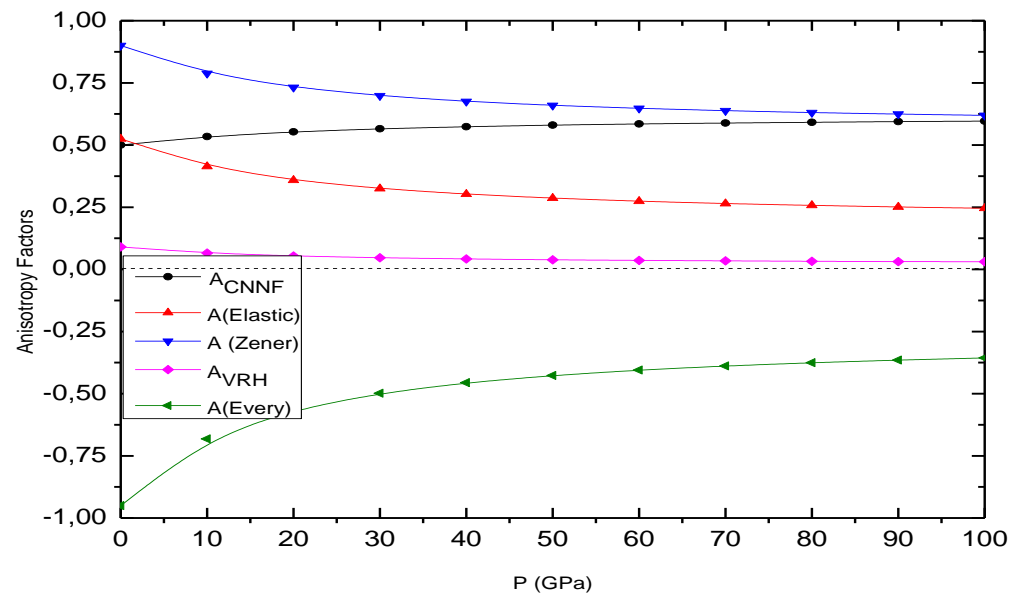

Figure 8: Change of anisotropy for Al-1.1Sc and Al-1.9Sc alloys.

\section{Result and Discussion}

It is understood from the analysis of Figures 1, 2 that the second degree elastic and volume constants of Al-1.1 Sc and Al-1.9 Sc alloys change linearly under high pressure. Accordingly, the linear equations for both alloys were obtained as; $\mathrm{C}_{11}(\mathrm{P})=\mathrm{C}_{11}(0)+5,15 \mathrm{P}, \mathrm{C}_{12}(\mathrm{P})=\mathrm{C}_{12}(0)+3,225 \mathrm{P}$ ve $\mathrm{C}_{44}(\mathrm{P})=\mathrm{C}_{44}(0)+1,45 \mathrm{P}$. Bulk constants: $\mathrm{B}(\mathrm{P})=\mathrm{B}(0)+3,8667 \mathrm{P}$ were obtained from the analysis of Figure 3. These results were consistent with the results obtained for different alloys under high pressure [17, 18, 20, 21]. It was also observed from the analysis of the results that the Sc ratio did not have any effect on the change of pressure. $\mathrm{A}=0$ is the isotropic condition of the elastic anisotropy of crystals (3). Although the alloys we studied are cubic, they are not isotropic $\left(\mathrm{C}_{12} \neq\right.$ $\mathrm{C}_{44}$ ). Anisotropy, defined as a measure of the intrinsic orientation of the crystals, is also a measure 
of good crystallization. It is understood that high pressure makes crystal orientations in these samples significantly, and therefore, better crystallization. Because the pressure, the size of the elastic anisotropy is markedly reduced, which means that it can both thicken the orientations in certain directions and makes the crystallization better. This explains the crystalline polarization of anisotropy $\Delta_{P}$ in [100] direction [20]. When Figure 4 is examined, it is seen that increased polarization increases with high pressure. Surface polarizations, $S_{1}$ and $S_{2}$, give information about the orientation of crystals on surfaces of (-110) and (001), respectively [20]. Figure 5 shows the positive effect of high pressure in both cases. The anisotropy of the $\mathrm{A}_{\mathrm{CNNF}}$ resulting from the closest neighborhood strength effect is calculated according to the pressure. Anisotropy was 0.5 in $\mathrm{P}=0$ and $\mathrm{P}=\mathrm{C}_{11}$ numerical equation and it was observed that it increased very high with high pressure. The reason for this is that in the nearest neighborhood the central force limits the crystal orientations.

In addition, taking $\mathrm{C}_{11}=$ Fixed, it was observed that this value increased faster up to the ideal value of elastic anisotropy $(\mathrm{A}=1)$ (Figure 6$)$. The size of the pressure at this point was calculated as $52.05 \mathrm{GPa}$. This pressure can be considered the highest limit for these alloys. Because in a different study related to $\mathrm{Al}_{3} \mathrm{Sc}$ applied pressure was restricted to $40 \mathrm{Gpa}$ [17].

Figure 7 shows that the results of $A_{E}, A_{Z}$ and $A_{V R H}$ elastic anisotropy vary with the high pressure. The change in $A_{E}$ shows that anisotropy increases with pressure, and in $A_{Z}$ it is in form of a decrease. And in both cases, alloys are far from isotropic condition.

\section{Conclusions}

In this study, it was concluded that the second degree elastic constants, volume constants and elastic anisotropy of Al-1.1Sc and Al-1.9Sc alloys changed significantly with high pressure but $\mathrm{A}_{\mathrm{CNNF}}$ and $\mathrm{A}_{\mathrm{VRH}}$ anisotropy changed very little. Moreover, it was seen that the ratio of Sc was not effective in the change of these parameters with pressure. It is concluded that the highest pressure that can be applied to these alloys is $52.05 \mathrm{GPa}$, which is anisotropic in both alloys.

\section{References}

[1] Nembach E., "Order strengthening: recent developments, with special reference to aluminumlithium alloys", 45, Prog. Mater. Sci., 4, Pergamon, (2000).

[2] Willey L.A., "Aluminum Scandium Alloy", United States Patent, US3619181A, (1971).

[3] Valiev R.Z., Salimonenko D.A, Tsenev N.K., Berdon P.B. and Langdon T.G., "Observations of high strain rate superplasticity in commercial aluminum alloys with ultrafine grain sizes", Scripta Materialia, 1997, 37 (12): 1945 - 1950.

[4] Lee S., Utsunomiya A., Akamatsu H., Neishi K., Furukawa M., Horita Z. and Langdon T.G., "Influence of scandium and zirconium on grain stability and superplastic ductilities in ultrafinegrained Al-Mg alloys”, Acta Materialia, 2002, 50 (3): 553 - 564.

[5] Morris D. G., "Mechanical behaviour of nanostructured material", Trans Tech Publications, 0878497978, Zürih, (1998).

[6] Valiev R. Z., Islamgaliev R. K., and Alexandrov I. V., "Bulk nanostructured materials from severe plastic deformation", Journal of Materials, 2000, 45 (2): 103 - 189.

[7] Murray J.L., "The Al-Sc (aluminum-scandium) system”, J. Phase Equilib., 1998, 19 (4), 380382.

[8] Hyland R. W., "Homogeneous nucleation kinetics of $\mathrm{Al}_{3} \mathrm{Sc}$ in a dilute Al-Sc alloy", Metall. Trans. A, 1992, 23 (7): 1947 - 1955. 
[9] Ocak H. Y., Uçgun E., Ünal R., "Experimental and first-principles investigation of the crystal structure of powder metallurgy Al-1.1Sc and Al-2Sc alloys", Transactions of Nonferrous Metals Society of China, 2013, 23 (10): 3020-3026.

[10] Royest J., and Ruym N., "Some comments on the misfit and coherency loss of $\mathrm{Al}_{3} \mathrm{Sc}$ particles in Al-Sc alloys", Scripta Materialia, 2005, 52 (12): 1275-1279.

[11] Royest J., and Ruym N.," Scandium in aluminium alloys" Int. Mater. Rev., 2005, 50 (1): 19 44.

[12] Roumina R., "Mechanical properties of a recoverd Al-Mg-Sc alloy", Doctor of philosphy, The Universtiy of British Columbia, (2002).

[13] Jones M. J., Humphreys F. J., "Interaction of recrystallization and precipitation: The effect of $\mathrm{Al}_{3} \mathrm{Sc}$ on the recrystallization behaviour of deformed aluminium", Acta Materialia, 2003, 51 (8): 2149-2159.

[14] Røyset J. and Ryum N.., "Scandium in aluminium alloys", International Materials Reviews, 2005, 50 (1): $19-44$.

[15] Royset J., Ryum. N., "Some comments on the misfit and coherency loss of $\mathrm{Al}_{3} \mathrm{Sc}$ particles in Al-Sc alloys", Scripta Materialia, 2005, 52 (12): 1275-1279.

[16]Dalen M. E., Dunand D. C., Seidman D. N., "Effects of Ti additions on the nanostructure and creep properties of precipitation-strengthened Al-Sc alloys", Acta Materialia, 2005, 53 (15): 4225-4235.

[17] Duan Y. H., Sun Y., Peng M.J., Zhou S. G., “Ab-initio investigations on elastic properties in L12 structure $\mathrm{Al}_{3} \mathrm{Sc}$ and $\mathrm{Al}_{3} \mathrm{Y}$ under high pressure", Journal of Alloys and Compounds, 2014, 585: 587-593.

[18] Asker C., Vitos L., Abrikosov I. A., "Elastic constants and anisotrpy and in FeNi alloys at high pressures from first-principles calculations", Physical Review B, 2009, 79 (21).

[19] Chantasiriwan S., Milstein F., "Embedded-atom models of 12 cubic metals incorporating second and third-order elastic moduli data", Physical Review B, 1997, 58 (10).

[20] Cohen R. E., Stixrude L., Wasserman E., "Tight-binding computations of elastic anisotropy of Fe, Xe and Si under compression", Physical Review B, 1997, 56 (14).

[21] Ellaway S. W., Faux D. A., "Effective elastic stiffnesses of InAs under uniform strain”, Journal of Applied Physics, 2002, 92 (6).

[22]Hanbücken, M., and Deville, J. P., "Stress and Strain İn Epitaxy Theoretical concepts, measurements and applications", Elsevier, Paris, (2001). 